City University of New York (CUNY) CUNY Academic Works

2018

\title{
A Cardiology Exhibit at a Science Museum, Viewed as Speech Acts in Sequence
}

David H. Lee

CUNY New York City College of Technology

\section{How does access to this work benefit you? Let us know!}

More information about this work at: https://academicworks.cuny.edu/ny_pubs/244

Discover additional works at: https://academicworks.cuny.edu

This work is made publicly available by the City University of New York (CUNY).

Contact: AcademicWorks@cuny.edu 


\section{Health Communication}

\section{A Cardiology Exhibit at a Science Museum, Viewed as Speech Acts in Sequence --Manuscript Draft--}

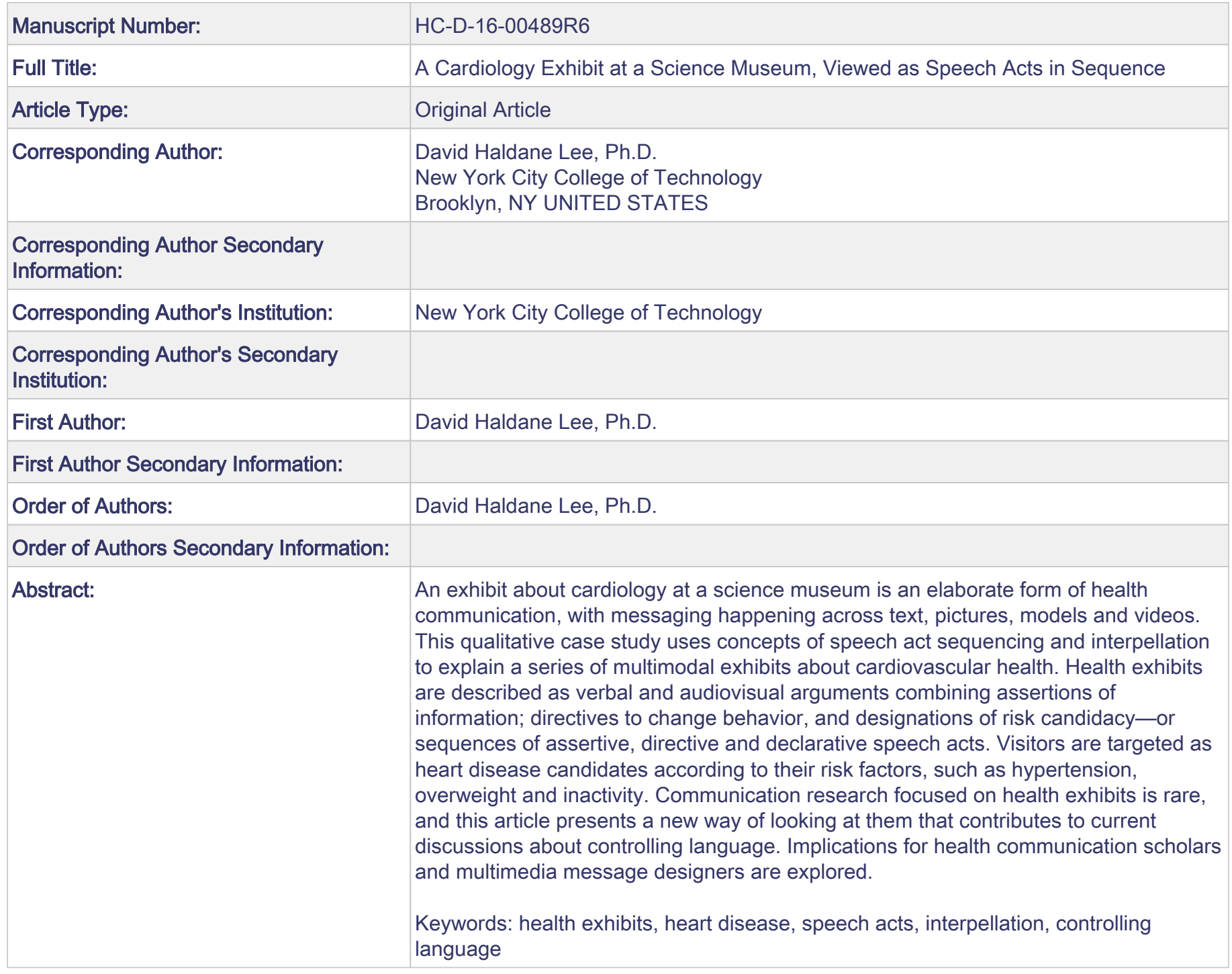


A Cardiology Exhibit at a Science Museum, Viewed as Speech Acts in Sequence

\begin{abstract}
An exhibit about cardiology at a science museum is an elaborate form of health communication, with messaging happening across text, pictures, models and videos. This qualitative case study uses concepts of speech act sequencing and interpellation to explain a series of multimodal exhibits about cardiovascular health. Health exhibits are described as verbal and audiovisual arguments combining assertions of information; directives to change behavior, and designations of risk candidacy — or sequences of assertive, directive and declarative speech acts. Visitors are targeted as heart disease candidates according to their risk factors, such as hypertension, overweight and inactivity. Communication research focused on health exhibits is rare, and this article presents a new way of looking at them that contributes to current discussions about controlling language. Implications for health communication scholars and multimedia message designers are explored.
\end{abstract}

Keywords: health exhibits, heart disease, speech acts, interpellation, controlling language 
A Cardiology Exhibit at a Science Museum, Viewed as Speech Acts in Sequence Health exhibits (HEs) are multimodal forms of medical advice found in science museums. In 2013, the most recent year that statistics are available, an estimated 95 million people visited science museums, worldwide (ATSC, 2014), which suggests a large audience for HEs. Kreps (2015) notes the importance of studying communication in a wide range of health promotion settings (p. 3), but there is a lack of scholarship about HEs from a health communication perspective. Multi-channel communication systems, with pictures, text, models, videos and interactive features, HEs are different from other science museum exhibits because visitors are motivated to have a personal stake in the information presented, related to their own health or that of loved ones. Because visitors encounter HEs as a series of factual assertions about the body along with directives to change their behavior (Hsu \& Lincoln, 2007, p. 20), they have a prescriptive (and not just descriptive) character. Additionally, HEs make predictions for "disease candidates" - i.e. those visitors who are at-risk because they smoke, have high blood pressure, or are overweight, etc.

Descriptive and prescriptive elements of messages are referred to, variously, as a distinction between "report" and "command" (Ruesch \& Bateson, 1951), "content" and “relationship" (Watzlawick, Bavelas, \& Jackson, 1967), or "assertive" and "directive" speech acts (Searle, 1976). This paper argues that HEs, composed of facts, orders and warnings, can be viewed as sequences of speech acts. In ethnographic descriptions of seven exhibits about cardiovascular health, "mechanisms of interpellation" (Baglia \& Foster, 2015) are identified that conscript science center visitors into the "subject position" (Davies \& Harre, 1990; Harré, 2008) of the disease candidate. The relatively subtle and seemingly objective process of interpellation forestalls for the visitor any alternative interpretation of the exhibits, other than viewing oneself 
as a 'patient-in-waiting,' in need of medical intervention. By characterizing exhibits as speech acts, “controlling language” (Brehm \& Brehm, 1981; Dillard \& Shen, 2005; Miller, Lane, Deatrick, Young, \& Potts, 2007) that makes audiences react negatively to health promotion messages can be identified. I hope this case study presents a novel perspective on health messaging that will be of interest to health communication researchers and practitioners working in multimedia settings.

\section{Site and Research Methods}

Case examples reported here are from a larger ethnographic study of The Amazing You (TAY), an exhibition at the Tampa Museum of Science and Industry (MOSI) focusing on diseases across the human lifespan. Health insurance companies, regional medical practices, device manufacturers and government agencies funded and helped design the exhibition. After IRB approval, data were collected over fall and winter of 2012-2013. Three of MOSI's top executives were interviewed at length to explain the process of conceiving, funding and designing TAY. Over 40 hours of video documenting my interactions with exhibits were downloaded to my computer and described textually, then coded in two stages to identify common themes. "Open coding” (Corbin \& Strauss, 2008, p. 62) involved categorizing elements of the exhibits, and "axial coding" (Corbin \& Strauss, 2008, p. 97) involved finding similarities between the open codes and combining them into several larger categories. Although surveys and interviews with visitors were conducted, none of the respondents mentioned the "Cardiology" exhibits, so their responses are omitted from this paper.

The idea for TAY came to MOSI's Chief Executive Officer after a life-threatening heart attack. While recovering he vowed to create a new kind of science museum exhibition that gave health advice, and not just factual information about bodily systems. MOSI hosted the Bodies 
exhibition in 2005, which used human remains, preserved by a process called plastination, to represent human anatomy. But according to the CEO, this exhibition lacked a "takeaway" message. "People were totally mesmerized by just...looking at the anatomy of the human body. It didn't tell you what not to do...it didn't tell you anything!" He explained that, for TAY, MOSI would address questions that were raised by Bodies but left unanswered, including "How do you maintain this system in the best working order as possible?" and "How do you detect things early while they are going on?" TAY was consistently described by MOSI executives as a kind of public health intervention that stressed screening for disease and lifestyle modification.

Based on what I learned from MOSI executives about the motives behind TAY, I began my analysis of the exhibition with this research question: Besides conveying information, what are these exhibits communicating? I tried to take an otherwise inductive approach, bracketing what I knew about health communication to avoid superimposing preconceived ideas on the emerging data. Inspired by grounded theory (Corbin \& Strauss, 2008), common themes were identified in the course of data collection and analysis, after which theoretical explanations were sought from extant scholarship. Using color codes and track changes, I categorized textual descriptions of the exhibits using action verbs, noting that some parts were "informing" while others were "warning," "risk-assessing," "suggesting" or "urging," etc. After this open coding process, I made a second pass over the text, seeing if there were codes similar enough to be aggregated into larger axial categories. For this paper, I collapsed over 20 open-codes into three: descriptive, prescriptive, and diagnostic. What follows are examples to illustrate this “dimensionalization” (Lindlof \& Taylor, 2011, p. 221) process.

For example, I coded a model of a clogged artery as "representing," and some text accompanying it as “explaining." Since they were anatomical descriptions and didn’t suggest any 
particular course of action, they were aggregated into a superordinate "descriptive" class. Short videos that seemed to me like advertisements for various surgical procedures were coded as “suggesting." An exhibit titled "Check How Much You Care” was coded as "instructing." Verbs such as suggesting and instructing were each prescribing a course of action for visitors, hence the "prescriptive" class. Then there were exhibits that involved visitors in listening to their own heartbeats using a stethoscope, or taking their own blood pressure. Because these are diagnostic technologies from clinical settings, they were coded as "diagnostic." Exhibits that listed risk factors for heart disease (like smoking or hypertension) were coded as "risk-assessing," and later grouped into the "diagnostic" category, because estimating one's own risk is a form of selfdiagnosis.

These descriptors of the communicative functions apparent in the "Cardiology" exhibits constitute a repertoire of speech acts that HEs perform. In addition to imparting information about health, the exhibits were giving advice, and singling out unhealthy behaviors as risk factors for disease. For “descriptive" elements, visitors behold information, phrased as statements of fact, even in primarily visual modes. For example, the model of the clogged artery can be seen as descriptive, with no particular health advice being offered. By contrast, "prescriptive" exhibits tell visitors what to do to avoid getting sick or to treat disease. "Diagnostic" exhibits obtain data from visitors' bodies, providing an opportunity for them to assess their own risk. In the next section, I describe the exhibits according to their descriptive, prescriptive and diagnostic aspects.

\section{Results}

The "Cardiology" exhibits are located in the dark, noisy "Adulthood" area of TAY. In the center, models of the heart, illuminated behind Plexiglas, were coded as descriptive. The next exhibit, entitled "In a Heartbeat," was coded as diagnostic, because visitors use a stethoscope to 
listen to their own chest cavity, and then compare those sounds with recordings of heart beats. Text explains that the "lub" sound is the mitral and tricuspid valves closing to prevent blood from going back into the atria. The "dub" sound that follows is the closing of the aortic and pulmonary valves. This "lub-dub" sound being normative, "defects in the system" are listed onomatopoetically, such as "lub-dub-wheeshh" or "lub-ssss-dub," which indicate valve leakage or blockage. This exhibit is multimodal because it reaches visitors across auditory and textual channels. Should a visitor's heartbeat sound abnormal compared to the sounds provided, they may recognize that they are the target audience for warnings about heart disease that follow.

Next, visitors can watch videos about "heart basics," heart failure, valve disease, congestive heart failure, heart attack and atrial fibrillation. Normal heart function is covered in the first video, with the rest focused on cardiac problems. Echocardiography, arteriography and other diagnostic procedures are illustrated, while atherectomy, balloon catheters and valvuloplasty are explained as surgeries for opening up blockages. These videos can be seen as descriptive, because they represent normal and pathological cardiac conditions, with no particular suggestion being made. However, by focusing on heart disease and medical interventions, the visitor is being positioned as mortal, aging, and a likely future consumer of medical procedures. In this sense, they are tacitly prescriptive.

The next exhibit, "Clogged Pipes" is a large 3D model of a cross-sectioned artery, with yellow globules constricting the vessel. A stanza of text lists "signs that you may have clogged arteries" including angina, shortness of breath, palpitations, weakness, dizziness, sweating, and erectile dysfunction. On the same list, lifestyle risk factors appear, including smoking, poor diet, inactivity, and being overweight. Note that symptoms and lifestyles are conflated on this "diagnostic" list, blurring the boundaries between signs of disease and behaviors. Finally, 
recommendations include "eating well," exercising, monitoring blood pressure and cholesterol, and obtaining a picture of one's arteries using medical imaging technologies. The model is descriptive of clogged arteries, but it is a description that warrants the diagnostic and prescriptive elements of the accompanying text. The ever-increasing focus on atherosclerosis is positioning visitors as patients-in-waiting.

To the left, an exhibit called "Caring for Your Sweetheart" focuses on preventing cardiovascular disease (CVD), and the prescriptive message becomes more overt. A stanza of text reads:

You are more likely to die of heart disease than any other reason. It is the number one killer of men and women. So it makes good sense to take good care of your heart for a long and healthy life.

The way the last sentence is phrased, with "So it makes good sense" at the beginning, makes it descriptive, syntactically, so the injunction to "take good care" is indirect.

Underneath, a chart entitled "Check How Much You Care" has three columns, each row containing statements, written in the first-person, from hypothetical CVD candidates. They describe their habits related to diet, exercise, smoking, and regular checkups, as well as information about their weight, blood pressure, and cholesterol. The left column is written from the perspective of a model, low-risk subject who does everything right:

I eat at least five servings of fruits and vegetables a day. I stay away from high fat foods. I do a good cardiovascular workout at least three times a week. I'm always active. I walk up the stairs rather than take the elevator...

Behind each cell, a green checkmark symbolizes approval. The subject in the middle column, who has no checkmark behind their assertions, likes processed foods and has no regular 
exercise routine. The subject in the right column describes him/herself as an overweight "couch potato" who smokes and loves salty snacks. A red X signifies disapproval in this column. Visitors are supposed to compare their own behaviors to the columns and identify with one of the three disease candidates. The first-person statements on display appear to be descriptive, but this exhibit is arguably diagnostic, because visitors use each statement to estimate their own heart disease risk.

The last exhibit, called "Go with the Flow" has a back lit male figure with blue veins and red arteries extending to the extremities. Visitors sit below on a stool, place their arm in an inflatable cuff, and have their blood pressure taken. The blood pressure monitor has a chart showing ranges from normal, prehypertensive, hypertension stage one and two, and "hypertensive crisis." This diagnostic exhibit triages visitors, assigning to them varying degrees of susceptibility and urgency.

\section{Discussion}

Like plaque builds up in the arteries, the "Cardiology" section of TAY is climax-ordered, stringing together descriptions, prescriptions and conscriptions into disease candidacy. The visitor is cornered into reckoning with their risk and adhering to disease prevention recommendations. The 'writing is on the wall,' as it were, because throughout this HE, words, sounds and images portend morbid outcomes. In the discussion that follows, I characterize the exhibits as speech acts in sequence, and suggest how they conscript visitors into disease candidacy. Finally, I elaborate on the concept of indirect directives, a term that is useful for identifying "controlling language" in health messages. 


\section{Describing, Prescribing and Diagnosing}

Messages that describe, prescribe and diagnose correspond to Searle's (1976) assertive, directive and declarative illocutionary types, which can be defined as follows: assertions are descriptive, true-false statements in the indicative mood, while directives are prescriptive (orders or suggestions), often in the imperative mood. An "indirect directive" (Searle, 1975) is a rephrased command, such as the statement "You're standing on my foot" serving as an implicit request (p. 66). Declaratives, or declarations, are speech acts that bring about changes by describing them as having occurred. For example, "this meeting is adjourned," as uttered by a chairperson, doesn't describe an already existing state of affairs; it makes it the case that the meeting is adjourned as a result of the proclamation. Each speech act is further illustrated below using examples from the "Cardiology" exhibits.

Assertive exhibits include the heart models, the videos and the clogged artery. They state facts about human anatomy and, on their own, don't tell visitors what to do. They often appear in sequence with directives that follow, or they may perform double-duty as indirect directives. For instance, videos about diagnostic procedures can be interpreted as assertions of fact as well as suggestions to undergo screening. The ever-increasing focus on heart disease in the videos positions visitors as patients-in-waiting who will likely need medical attention in the future. Other apparently assertive exhibits acting as indirect directives include the last sentence in the "Caring for Your Sweetheart" exhibit. The sentence reads "So it makes good sense to take good care of your heart for a long and healthy life." The second half of that sentence, "take good care of your heart for a long and healthy life" could stand on its own as an imperative. However, the way the sentence is phrased, with "So it makes good sense" at the beginning, turns it into an 
assertion, syntactically, making the directive indirect. There are also some imperatives, such as "Check How Much You Care" and "Go With the Flow."

Declarations are speech acts that, by being uttered, bring about some new turn of events. They both describe the way things are at the same time that they change the way things are (Searle, 1976, p. 14). Diagnosis is considered to be a speech act of this type, because it assigns to the patient a new identity, complete with rights and duties (Sadegh-Zadeh, 2011; Schulz, 2006). For example, the patient may be exempted from the usual social obligations (Parsons, 1951). They might take sick leave, or join affinity groups of others with the diagnosis. They are also expected to seek medical attention and adhere to treatment recommendations. Arguably, the diagnostic affordances of HEs are declarations that can bring about a new social reality for the visitor. These relatively low-tech diagnostic technologies can effectively declare that visitors have (or are at-risk for) heart disease, insofar as their readings are abnormal.

Diagnostic exhibits perform declarative speech acts because they classify visitors as disease candidates according to their lifestyles and metrics. In the exhibit where visitors compare their behavior with three different risk profiles, should they identify with the chain-smoking couch potato, it is for them "for whom the bell tolls," poetically speaking. The concept of interpellation (Althusser, 1971), describes how people come to recognize themselves as the target audience of a message.

\section{Interpellation}

I claim that, as they encounter the exhibits, visitors are interpellated into disease candidacy, a subject position with medical and behavioral entailments. This claim is meant to approach a larger question for health communication researchers. That is, how do people come to recognize themselves as "patients-in-waiting," even in the absence of symptoms? How does 
medical ideology constitute subjectivities of disease risk, necessitating interventions?

Multimedia speech act sequences, as present in HEs, present an opportunity to research such interpellative mechanisms.

As defined by Baglia and Foster (2015), interpellation is a process whereby "audience members fulfill their participation in an ideological truth" (p. 53). Authoritative institutions (such as medical practices or science centers) "recruit" or "hail" individuals, constituting them as subjects (Althusser, 1971, p. 174). In a museum environment, interpellation is more than just a mental phenomenon. According to Dickinson, Ott, and Aoki (2006, p. 35), "It also engages the body, shifts its attention, and does its work visually, aurally, and haptically", which implies multimodal means of interpellation.

Frank (1998) equates diagnosis with interpellation, noting how pre-symptomatic persons can be hailed: "To have 'risk factors' is to be a virtual patient, not yet sick, but hailed as one who is a medical subject with the restrictions and responsibilities that attach to that status" (Frank, 1998, p. 34). A diagnosis, even made outside of a medical setting, positions a visitor as the intended addressee of a warning, obligating them to assume the position of being at-risk. At TAY, the subject position of disease candidate is constituted using declarative speech acts acting in concert with assertives and directives. Their sequential description in this research is intended to offer one account of the mechanisms of interpellation, expanding on recent scholarship (Aston, 2009; Baglia \& Foster, 2015; Ruthven, 2016).

\section{Speech Act Sequences}

These findings show that assertions of fact don't stand alone as speech acts. Instead, they couple with directives or declarations, and this reveals an explanatory shortcoming of speech act theory. A problem with treating a single utterance as a self-contained speech act is the difficulty 
of determining its meaning outside of the episode in which it appears (Frentz \& Farrell, 1976, p. 337). With its focus on the sentence as the primary unit of analysis (Searle \& Vanderveken, 2005, p. 109), speech act theory doesn't account for the ways that illocutionary acts build upon one another sequentially (Searle, 1992, p. 11). Conversational analysis makes use of act sequencing notions, but in face-to-face contexts where dialogue is back and forth (Cooren, 2005;

Geis, 2006; van Dijk, 1977). HEs described here are, by contrast, one-way messages with words, sounds and images. Despite "pseudo-interactive" (Heath \& vom Lehn, 2008) affordances such as buttons to push, MOSI is doing all the talking. Literature on act sequences is instructive, but the concept needs to be adapted to explain HEs.

This analysis of the "Cardiology" exhibits offers a way of identifying speech acts in sequence. When treated as a situation of "secondary orality" (Ong, 1982, p. 136), HEs can be classified as speech acts, which presupposes that they need not be spoken utterances. The "Cardiology" area can be seen as a directive, overall, composed of smaller component speech acts. Visitors are not just learning new things: they are being challenged to recognize their own risk for CVD and instructed to make what may be dramatic lifestyle changes. Because directives and declarations require some evidential basis, they often couple with assertions of fact. Indeed, assertions are polysemic, in that they can also function as declarations or indirect directives.

\section{Imperatives Versus Indirect Directives}

An unexpected result of this research is that it reveals some conceptual confusion about controlling language in health messages. Controlling language is characterized by "increased use of imperatives (i.e. commands and orders) as opposed to propositions or indirect suggestions" (Miller et al., 2007, p. 223). It can elicit reactance (Brehm \& Brehm, 1981; Dillard \& Shen, 2005; Miller et al., 2007), which refers to a counter-persuasive outcome. Indirectness is preferred 
to avoid the impression of controlling motives, and imperatives rephrased as assertions are less explicitly controlling. While instances of imperatives and indirect directives appear in health communication message design literature, they aren't always referred to using that terminology and their differences can go unidentified. In what follows I provide some examples where identifying the difference in sentence type might provide greater clarity.

A Centers for Disease Control and Prevention webpage called "What is Health Communications" poses the following question: "Take a look at these sentences. What do the bold words have in common? Fasten your seat belt. Eat more fruit. Pull over to use your cell phone. Don't litter. Get a mammogram. Talk to your doctor" (CDC, 2011). Each bolded word is a present tense verb starting off a sentence in the imperative grammatical mood, but they are not identified as such. According to the CDC, "These words describe problems to be addressed by changing behavior" (CDC, 2011), yet they are, more accurately, prescriptive rather than descriptive.

In another example of imperatives going unidentified, Parrott (1995) revises the wording of a Skin Cancer Foundation pamphlet. Instead of stating "Know the signs of skin cancer" (quoted in Parrot, 1995, p. 10) Parrot suggests the alternative wording: "Knowing these signs of skin cancer can help you detect any unusual skin conditions before they become a serious health problem" (Parrot, 1995, p. 11). Here, an imperative is reworded as an indirect directive, in order to present the content "in an unusual way" that "explicitly state[s] a basic motive to attend rather than stating a clinical directive" according to Parrot (1995, p. 11). Yet while the motive to attend is now specified, the directive becomes inexplicit in the revised sentence, making the "explicit" descriptor misleading. 
Not all health message designers discourage the use of imperatives. A U.S. Department of Health and Human Services webpage suggests an imperative for the sake of plainer language. Instead of "The Dietary Guidelines for Americans recommends a half hour or more of moderate physical activity on most days, preferably every day..." the HHS would change it to "Do at least 30 minutes of exercise, like brisk walking, most days of the week." (cited in Jensen, 2012, p. 183). Because it is lexically simpler, the explicit command is preferred to aid comprehension for those with low health literacy, but the HHS doesn't note the mood change. Besides not noting the distinction, this example indicates a lack of consensus about the appropriate use of imperatives.

There are other examples in the literature about controlling language where a distinction between direct and indirect directives would add greater clarity. For example, in one study, descriptive clauses such as "smoking is cool" and "smoking makes you look more mature" are said to be examples of "explicit" pro-smoking messages, even though they "did not explicitly tell students to go purchase a pack of cigarettes" (Grandpre, Alvaro, Burgoon, Miller, \& Hall, 2003, pp. 355-356). This implies that indirect directives are explicit. Another study refers to “imperatives such as 'must' or 'need"” (Quick \& Stephenson, 2008, p. 450) but these are modal auxiliaries, not imperatives. These examples indicate that, in the definition of controlling language, the correct and consistent terminology is needed to distinguish between "imperatives" and "indirect suggestions" (Miller et al., 2007, p. 223) — a distinction provided by the indirect directive concept.

\section{Conclusion}

This analysis of an HE through the lens of speech act sequences and interpellation has implications for health communication scholars as well as health promotion practitioners. Those scholars concerned with controlling language in health messages are prompted to adopt a more 
precise terminology for distinguishing between imperatives and indirect directives. Health promoters and message designers, especially those working in multimodal environments, are reminded that, besides informing audiences, health messages act upon them in other ways, including making requests and conscripting them into risk profiles. Understanding how speech acts build upon each other sequentially helps surface the communicative intentions beneath multimedia health promotion messages.

The "Cardiology" exhibits at MOSI do more than state facts, given their sequential combination of assertions, predictions, warnings and action steps that subjectify visitors as the target audience. The descriptive, prescriptive and diagnostic elements, considered as speech acts, reveal mechanisms of interpellating visitors into disease candidacy. Besides showing the explanatory potential of concepts presently under-represented in health communication literature, viewing multimodal messages as act sequences and interpellative mechanisms helps to expand health communication inquiry into as yet unresearched museum environments. 


\section{References}

Althusser, L. (1971). Ideology and ideological state apparatuses (Notes towards an investigation). In B. Brewster (Trans.), Lenin and philosophy and other essays (pp. 127186). New York, NY: Monthy Review Press.

Aston, S. (2009). Identities under construction: Women hailed as addicts. Health: An Interdisciplinary Journal for the Social Study of Health, Illness and Medicine, 13, 611628. doi:10.1177/1363459309341865

ATSC. (2014). 2013 science center and museum statistics. Retrieved from http://www.astc.org/wp-content/uploads/2014/10/2013-Science-Center-Statistics.pdf

Baglia, J., \& Foster, E. (2015). Mad men as health communication: Health-related themes in the hit AMC television series. Health Communication, 30, 50-60.

doi:10.1080/10410236.2013.835782

Brehm, S. S., \& Brehm, J. W. (1981). Psychological reactance: A theory of freedom and control. New York, NY: Academic Press.

CDC. (2011). What is health communications? Retrieved from https://www.cdc.gov/healthcommunication/healthbasics/WhatIsHC.html

Cooren, F. (2005). The contribution of speech act theory to the analysis of conversation. In K. L. Fitch \& R. E. Sanders (Eds.), Handbook of language and social interaction (pp. 21-40). New York, NY: Psychology Press.

Corbin, J. M., \& Strauss, A. L. (2008). Basics of qualitative research: Techniques and procedures for developing grounded theory (3rd ed.). Los Angeles, CA: Sage Publications. 
Davies, B., \& Harre, R. (1990). Positioning: The discursive production of selves. Journal for the Theory of Social Behaviour, 20, 43-63. doi:10.1111/j.1468-5914.1990.tb00174.x

Dickinson, G., Ott, B. L., \& Aoki, E. (2006). Spaces of remembering and forgetting: The reverent Eye/I at the Plains Indian Museum. Communication and Critical/Cultural Studies, 3, 27-47. doi:10.1080/14791420500505619

Dillard, J. P., \& Shen, L. (2005). On the nature of reactance and its role in persuasive health communication. Communication Monographs, 72, 144-168. doi:10.1080/03637750500111815

Frank, A. W. (1998). Enacting illness stories: When, what and why. In H. L. Nelson (Ed.), Stories and their limits: Narrative approaches to bioethics (pp. 31-49). New York: Routledge.

Frentz, T. S., \& Farrell, T. B. (1976). Language-action: A paradigm for communication. Quarterly Journal of Speech, 62, 333-349. doi:10.1080/00335637609383348

Geis, M. L. (2006). Speech acts and conversational interaction. Cambridge, England: Cambridge University Press.

Grandpre, J., Alvaro, E. M., Burgoon, M., Miller, C. H., \& Hall, J. R. (2003). Adolescent reactance and anti-smoking campaigns: A theoretical approach. Health Communication, 15, 349-366. doi:10.1207/s15327027hc1503_6

Harré, R. (2008). Positioning theory. Self-Care \& Dependent-Care Nursing, 16(1), 28-32.

Heath, C., \& vom Lehn, D. (2008). Configuring 'interactivity': Enhancing engagement in science centres and museums. Social Studies of Science, 38(1), 63-91. doi:10.1177/0306312707084152 
Hsu, H. L., \& Lincoln, M. (2007). Biopower, bodies... the exhibition, and the spectacle of public health. Discourse, 29, 15-34.

Jensen, J. D. (2012). Addressing health literacy in the design of health messages. In H. Cho (Ed.), Health communication message design: Theory and practice (pp. 171-190). Thousand Oaks, CA: Sage Publications.

Kreps, G. L. (2015). Evaluating health communication programs to enhance health care and health promotion: A state of the art review. Journal of Health Communication, 19, 14491459. doi:10.1080/10810730.2014.954080

Lindlof, T. R., \& Taylor, B. C. (2011). Qualitative communication research methods (3rd ed.). Thousand Oaks, CA: Sage Publications.

Miller, C. H., Lane, L. T., Deatrick, L. M., Young, A. M., \& Potts, K. A. (2007). Psychological reactance and promotional health messages: The effects of controlling language, lexical concreteness, and the restoration of freedom. Human Communication Research, 33, 219240. doi:10.1111/j.1468-2958.2007.00297.x

Ong, W. J. (1982). Orality and literacy: The technologizing of the word. London, UK: Routledge.

Parrott, R. L. (1995). Motivation to attend to health messages: Presentation of content and linguistic considerations. In E. W. Maibach \& R. Parrott (Eds.), Designing health messages: Approaches from communication theory and public health practice (pp. 7-23). Thousand Oaks, CA: Sage Publications.

Parsons, T. (1951). The social system. Glencoe, IL: Free Press. 
Quick, B. L., \& Stephenson, M. T. (2008). Examining the role of trait reactance and sensation seeking on perceived threat, state reactance, and reactance restoration. Human Communication Research, 34, 448-476. doi:10.1111/j.1468-2958.2008.00328.x

Ruesch, J., \& Bateson, G. (1951). Communication, the social matrix of psychiatry. New York, NY: Norton.

Ruthven, J. S. (2016). "Making it personal": Ideology, the arts, and shifting registers in health promotion. AIDS Care, 28(Suppl. 4), 72-82. doi:10.1080/09540121.2016.1195485

Sadegh-Zadeh, K. (2011). The logic of diagnosis. In F. Gifford (Ed.), Handbook of philosophy of science: Philosophy of medicine (Vol. 16, pp. 357-424). Oxford, UK: Elsevier.

Schulz, P. J. (2006). The communication of diagnostic information by doctors to patients in the consultation. In V. Kalitzkus \& P. L. Twohig (Eds.), Bordering biomedicine (pp. 103118). Amsterdam, Netherlands: Rodopi.

Searle, J. R. (1975). Indirect speech acts. In P. Cole \& J. Morgan (Eds.), Syntax and semantics (pp. 59-82). New York: Academic Press.

Searle, J. R. (1976). A classification of illocutionary acts. Language in Society, 5, 1-23. doi:10.1017/s0047404500006837

Searle, J. R. (1992). Conversation. In H. Parrett \& J. Verschueren (Eds.), (On) Searle on conversation (pp. 7-30). New York, NY: Benjamins.

Searle, J. R., \& Vanderveken, D. (2005). Speech acts and illocutionary logic. In D. Vanderveken (Ed.), Logic, thought and action (Vol. 2, pp. 109-132). Amsterdam, Netherlands: Springer.

van Dijk, T. A. (1977). Text and context: Explorations in the semantics and pragmatics of discourse. New York, NY: Longman. 
Watzlawick, P., Bavelas, J. B., \& Jackson, D. D. (1967). Pragmatics of human communication: A study of interactional patterns, pathologies, and paradoxes. New York, NY: Norton. 
Running head: A CARDIOLOGY EXHIBIT AT A SCIENCE MUSEUM

A Cardiology Exhibit at a Science Museum, Viewed as Speech Acts in Sequence

\author{
David Haldane Lee \\ Department of Humanities \\ CUNY New York City College of Technology
}

Acknowledgements: Thanks to MOSI participants, and to the anonymous reviewers for their helpful comments.

Correspondence concerning this article should be addressed to David H. Lee, Department of Humanities, Room A630, New York City College of Technology, 300 Jay St, Brooklyn, NY 11201

Contact:dlee@ citytech.cuny.edu 